\section{A OPINIÃO PÚBLICA DA SOCIEDADE MERCOSULINA E OS CAMINHOS DO BLOCO NOS ANOS 2010}

\author{
THE PUBLIC OPINION OF MERCOSULINE SOCIETY \\ AND THE PATHWAYS OF THE BLOCK IN 2010'S
}

\author{
CAMILLA SILVA GERALDELLO • \\ Instituto de Gestão Pública e Relações Internacionais \\ (IGEPRI) (Brasil). \\ E-mail: camillageraldello@gmail.com
}

\section{Resumo}

O objetivo desse trabalho é verificar qual o modelo de inserção internacional do Mercosul apoiado pelos cidadãos dos países do bloco na década de 2010. O Mercosul passou por mudanças de ênfase em decorrência do cenário internacional e das políticas externas dos membros. Se durante os anos 1990, o bloco e os membros foram guiados pelo neoliberalismo e por relações com parceiros tradicionais, a partir dos anos 2000 , as políticas sociais ganharam destaque e os membros apostaram na diversificação de parceiros comerciais. Todavia, a partir de 2015 o Mercosul entrou em novo momento de mudança com o redirecionamento político, à centro-direita, de alguns países sul-americanos. Dessa forma, procuramos mostrar por meio dos dados do Latinobarómetro de 2010 a 2016 para qual direção a sociedade mercosulina deseja se mover: se para fortalecimento das relações Sul-Sul ou das relações Norte-Sul; se para o incremento de relações via comércio ou via políticas sociais.

\section{Registro bibliográfico}

SILVA GERALDELLO, CAMILLA «A opinião pública da sociedade mercosulina e os caminhos do bloco nos anos 2010", en: ESTUDIOS SOCIALES, revista universitaria semestral, año XXIX, $n^{\circ} 56$, Santa Fe, Argentina, Universidad Nacional del Litoral, enero-junio, 2019, pp. 203-226.

\section{Abstract}

The objective of this study is to verify the Mercosur model of international insertion supported by the citizens of the countries of the bloc in the 2010's. Mercosur has undergone some changes of emphasis due to the international scenario and members' external policies. If during the 1990's the bloc and members were guided by neoliberalism and relations with the traditional poles of power, from the 2000s social policies gained prominence in the bloc's agenda and member countries bet diversification of trading partners. However, since 2015 Mercosur enters a new moment of change with the political redirection, the center-right, of some South American countries. In this way, we try to show through the data of the Latinobarómetro from 2010 to 2016 which direction Mercosur society wants to move: whether to strengthen South-South relations or North-South relations; to increase relations through trade or through social policies.

\section{Descriptores · Describers}

Mercosul / opinião pública / política externa Mercosur / publicopinion / foreignpolicy

Recibido: 08/08/2017 Aceptado: 08/05/2018 


\section{INTRODUÇÃO}

A intensificação da globalização econômica mundial, somada ao processo de encerramento da Guerra Fria, levou muitos países no fim dos anos 1980 e início dos anos 1990 a aderirem a processos de integração regional ${ }^{1}$. Na América Latina, a Comissão Econômica para América Latina e Caribe (CEPAL) elaborou o conceito de «regionalismo aberto», o qual combinava «liberalização comercial entre os parceiros do bloco regional com políticas de liberalização em relação a terceiros países» (CORAZZA; HERRERA, 2006: II). É neste contexto que ocorre o nascimento do Mercado Comum do Sul (mercosul) entre Argentina, Brasil, Paraguai e Uruguai em I99I.

Todavia, a constituição doMercosul foi além da proposta de «regionalismo aberto» da Cepal, incluindo não somente a liberalização comercial, mas também políticas de proteção externa por meio da instituição de uma união aduaneira. Essa decisão, segundo Veiga e Rios (2007), foi «influenciada pelas preferências comerciais e por consideraçóes de política externa do Brasil» que desejava preservar mercados e fortalecer seu poder de barganha por meio de economia de escala e ganhos de eficiência das cadeias produtivas integradas entre os quatro países para negociar com os países desenvolvidos do Norte. Os autores também acreditam que Argentina, Paraguai e Uruguai aceitaram a «hegemonia brasileira na definição do modelo de integração e da tarifa externa comum do bloco» (VEIGA y RIOS, 2007: I2).

Nesse sentido, ao relacionarmos o nascimento e desenvolvimento do bloco ao longo dos anos com a política externa brasileira (РEB), percebemos pontos de contato, como a preferência pelos países desenvolvidos nos anos I990 da PEB e a forte expectativa do Mercosul em fechar um acordo comercial com a recémconstituída União Europeia (UE); e ainda a mudança no enfoque da PEB dos anos 2000, que passou a priorizar as relaçóes Sul-Sul, em momento que foi privilegiado o fortalecimento político e social do Mercosul, em detrimento da busca ferrenha em realizar acordos comerciais com grandes parceiros.

1] Agradeço a André Luis Silva Eiras e aos pareceristas de EstudiosSociales pela leitura da versão preliminar desse texto. Eventuais limitações são de responsabilidade da autora. Uma versão em espanhol deste trabalho foi apresentada no I CongresoLatinoamericano de Integración Regional y DesarrolloSostenible, realizado em Bogotá entre 21 e 22 de junho de 2018, organizado pelo Grupo de Reflexión sobre Integración y Desarrollo em America Latina y Europa (GRIDALE). 
Mas esse movimento não ocorre somente com a política externa brasileira. Também vemos pontos de contato das políticas externas argentina, paraguaia, uruguaia e venezuelana com as açóes do bloco, como será observado. Desse modo, apesar de existir um insulamento entre a formulação e condução da política externa com a sociedade, como apontam Almond e Lippmann (HOLSTI,I992), partimos do pressuposto de que a política externa é uma política pública e percebe as demandas da sociedade. Assim, com as novas possíveis direçóes doMercosul a partir de 20I5, devido à chamada "guinada à direita» de alguns países da América do Sul², cabe a pergunta: qual o modelo de inserção internacional doMercosulapoiado pelos cidadãos dos países-membros? Via relação Sul-Sul? Via relação Norte-Sul? Via comércio? Via políticas sociais? Existe relação entre o desejo da sociedade mercosulina e as (possíveis) açóes implementadas pelos governos do bloco em termos de política externa? ${ }^{3}$

Nossa hipótese é que a sociedade mercosulina percebe as novas tendências mundiais, de emergência de novos polos de poder e enfraquecimento de polos tradicionais, porém, mantém-se fechada ao livre-comércio por preocupar-se com os custos advindos dessa opção. E, indo em direção contrária ao consenso de Almond-Lippmann ${ }^{4}$, acreditamos que o modelo de inserção internacional do Mercosul oscila de modo semelhante e próximo ao desejo dessa sociedade 5 .

2] Diversos autores vêm trabalhando com esse tema, ver, por exemplo: MAYORGA (2016); CASARÕES (2016); MARQUES (2016). Todavia, não apenas a América do Sul passa por essa "guinada», mas também os países desenvolvidos (ver PONTES, 2017).

3] Um modelo de inserção internacional pressupõe diretrizes e parâmetros para a atuação de um país no cenário internacional visando atingir seus objetivos e metas nesse ambiente. Essas diretrizes e parâmetros se traduzem em «atitudes diante de blocos, coalizões, parcerias e prioridades regionais» (CERVO; LESSA, 2014: 139). É essa tradução do modelo de inserção internacional que será verificada ao longo do texto ao se avaliar a opinião pública mercosulina, já que «as pressões sistêmicas devem se traduzir por meio de variáveis intervenientes no nível doméstico» (SCHENONI, 2012: 36).

4] Segundo HOLSTI (1992), o fim da Segunda Guerra Mundial proporcionou um amplo consenso, o "consenso Almond-Lippmann», sobre a opinião pública e política externa, o qual é pautado nas seguintes premissas: (1) a opinião pública é volátil e, portanto, fornece bases inadequadas para políticas externas estáveis e efetivas; (2) falta coerência ou estrutura à opinião pública; e (3) na análise final, a opinião pública tem pouco ou nenhum impacto sobre política externa.

5] ARBILLA (2000) também parte da premissa de que as variáveis domésticas foram intermediadoras e tradutoras da recepção das novas correntes hegemônicas globais no processo de formulação das políticas externas argentina e brasileira entre 1989 e 1994. 
Para testar nossa hipótese, faremos um breve histórico da evolução do bloco, focando na década de 2oro, e delinearemos o pensamento da sociedade mercosulina sobre os polos de poder, aspectos que influenciam no desenvolvimento dos países e efeitos da integraçáo do país com o mundo por meio dos dados dos surveys do Latinobarómetro de 2010, 20II, 2013, 2015, 2016 e 2017, o que nos possibilitará traçar o tipo de inserçâo internacional apoiada pela população dos cinco países membros do bloco ${ }^{6}$. Com esse perfil traçado, analisaremos as açóes do bloco a partir dos anos 2010 na tentativa de encontrar uma convergência entre ambos.

\section{0 CAMINHO DO MERCOSUL:}

\section{OS 28 ANOS DO BLOCO E AS POLÍTICAS EXTERNAS DOS MEMBROS}

Desde a década de 1950 existem discussōes sobre a formação de um mercado econômico regional na América Latina, o qual se tentou concretizar em I960 com a formação da Associação Latino-Americana de Livre Comércio (ALALC). Entretanto, a ALALC não gerou os resultados esperados e foi sucedida pela Associação LatinoAmericana de Integração (ALADI), criada em I980 (CORAZZA; HERRERA, 2006). Nessa mesma década, Brasil e Argentina assinam, em 1985, a Declaração do Iguaçu, com o objetivo de «criar um Grupo de Trabalho Conjunto de alto nível, presidido pelos Ministros de Relaçôes Exteriores dos dois países e firmar os compromissos de cooperação nuclear pacífica» (OLIVEIRA,I998: I4). Desse modo, as relaçóes entre Brasil e Argentina dos anos 1980 integravam três variáveis fundamentais - «uma militar-estratégica, outra política e outra econômica» (HIRST,1987: 59).

Posteriormente os dois países assinam em 1988 o Tratado de Integração, Cooperação e Desenvolvimento estabelecendo um mercado comum, ao qual outros países latino-americanos poderiam se unir. Com a antecipaçáo do prazo para a formação do mercado comum, Paraguai e Uruguai decidem aderir ao Tratado de Cooperação e Desenvolvimento entre Brasil e Argentina por meio do Tratado de

6] Utilizamos somente os dados do Latinobarómetro, pois mesclar outras bases de dados significaria usar metodologias diferentes, realizando uma aproximação temática entre as perguntas dos questionários. Isso poderia levar a aproximações equivocadas ou a adaptações que não condizem com a realidade. No próprio Latinobarómetro encontrou-se questionários com questões ou alternativas diferentes em anos diversos. Dessa forma, optou-se por elencar apenas uma base de dados para que as perguntas do questionário fossem utilizadas as questões exatamente iguais. 
Assunção em 26 de março de I99I, formando assim o Mercado Comum do Sul (oliveira, 1998). Porém, é apenas em 1994 que o bloco adquire personalidade jurídica com a assinatura do Protocolo de Ouro Preto.

OMercosul nascia com 3 objetivos primordiais:a «livre circulação de bens, serviços e fatores produtivos entre os países»; o «estabelecimento de uma tarifa externa comum e a adoção de uma política comercial comum»; e a "coordenação de políticas macroeconômicas e setoriais», os quais seriam alcançados por meio da harmonização das legislações dos Estados-membros nas áreas pertinentes (DECRETO $\mathrm{N}^{\circ}$ 350, 199I). Contudo,

«Dadas as características da tarifa externa comum (TEC) negociada em I994 -a qual praticamente reproduzia a tarifa do Brasil- os países menores concentraram esforços de negociação no estabelecimento de mecanismos transitórios que lhes permitissem manter práticas e instrumentos que seriam incompatíveis com a tarifa acordada no bloco e com a ideia de uma política comercial comum. Essa forma de resolver as tensões e conflitos entre interesses muito diferentes dos países-membros, no que se refere ao desenho da política comercial, gerou grande quantidade de perfuraçóes da tarifa externa comum e praticamente inviabilizou a extensão dos compromissos sub-regionais a outras dimensões (não tarifárias) da política comercial comum» (VEIGA E RIOS, 2007: I2).

Nesse sentido, a maneira escolhida para resolver conflitos de interesses comerciais entre os membros dificultou a implementação dos principais instrumentos de uma uniáo aduaneira, o que se refletiu nas negociaçóes comerciais extrabloco (VEIGA E RIOS, 2007). Ainda segundo os autores, as dificuldades do bloco deveriam acentuar-se com a incorporação da Venezuela, país com características econômicas muito distintas dos membros fundadores (VEIGA E RIOS, 2007). Entretanto, no aspecto político e social o bloco avançou ao longo dos anos 2000.

Em 2005 foi criado o Fundo para a Convergência Estrutural do Mercosul (FOCEM), cujas operaçóes começam em 2007, com o objetivo de financiar projetos de infraestrutura nos países do bloco, especialmente voltado para Paraguai e Uruguai. Já em 20 oo foi aprovado o Plano Estratégico de Ação Social (pEAs), visando «erradicar a fome, a pobreza e combater as desigualdades sociais; [...] universalizar a saúde pública; universalizar a educação e erradicar o analfabetismo; valorizar e promover a diversidade cultural», entre outros fins (GUILHERME; REIS, 20I8: II2). O PEAS começou a ser implementado em 20I2, mesmo ano em que 
ocorre a inclusão Venezuela e a assinatura do primeiro Protocolo para adesão da Bolívia ${ }^{7}$ (GAZZOLA; ARAÚjO, 20I8).

Dessa forma, se o bloco começa sua jornada focado na economia, ao longo do século XXI, a preocupação volta-se para a infraestrutura e questôes sociais dos países-membros. Isso porque a partir dos anos 2000 (res)surgem resistências quanto à abertura econômica e liberalização comercial (mesmo a regional) e ocorrem mudanças políticas nos países do bloco com a eleição de presidentes com orientaçôes à esquerda e à centro-esquerda no espectro político. Já, a partir de meados dos anos 20Io, com novas mudanças políticas no comando de Argentina e Brasil, principalmente, e orientaçóes mais à direita desses governos, o bloco volta a focar na abertura econômica, recolocando o acordo Mercosul-ue como tema central de discussão. Assim, o caminho percorrido pelo Mercosul ao longo dos seus 28 anos de existência traçado brevemente aqui aconteceu em paralelo com a formulação e implementação de política externa de seus membros.

\section{As políticas externas dos membros do Mercosul}

Como exposto acima, o processo de criação do Mercosul inicia-se devido ao entendimento bilateral de Brasil e Argentina ${ }^{8}$. Ambos os países foram influenciados pelo neoliberalismo predominante na década de 1990 e passaram por fortes aberturas comerciais nesse período, prejudicando muitas indústrias nacionais. Já nos anos 2000, Brasil e Argentina foram influenciados pelo crescimento chinês, que gerou «rápida expansão da demanda internacional por [produtos agrícolas] e forte aumento no preço [desses produtos]" (MACADAR, 2009: 7), fazendo com que o destaque internacional da agricultura desses países fosse mantido. Além disso, a China assumiu posiçóes proeminentes como parceira comercial dos dois países: superou o primeiro lugar dos Estados Unidos na relação com o Brasil e o segundo lugar dos Estados Unidos na relação com a Argentina9 (OBSERVATORY OF ECONOMIC COMPLEXITY, 2OI7; MACADAR, 2009).

7] Como o Paraguai estava suspenso a época um novo Protocolo de adesão da Bolívia ao Mercosul foi firmado em 2015 (GAZZOLA E ARAúJO, 2018).

8] Sobre o assunto ver OLIVEIRA (1998).

9] O Brasil ocupa a primeira posição como principal parceiro comercial argentino (OBSERVATORY OF ECONOMIC COMPLEXITY, 2017). 
De acordo com BERNAL-MEZA (I999: 46), a orientação da política externa brasileira nos anos 1990 seguira tendências identificadas desde meados dos anos 1970, notadamente as ideias desenvolvimentistas e autonomistas. Assim,

«[e]nquanto, a política externa do fim da Ditadura e do Governo Sarney (1985-1990) foi pautada ainda pela lógica herdada da Guerra Fria da autonomia pela distância, a política externa de FHC (1995-2002) buscou ser autônoma participando e se integrando ao sistema internacional e a política externa de Lula (2003-2010), por fim, buscou integrar-se ao sistema internacional por meio da diversificação de parceiros e de opçôes estratégicas» (GERALDELlO, 20I4: I22).

O início do século XXI no Brasil marca a ampliação das relações com novos polos de poder, como a China, um diálogo mais equilibrado com os Estados Unidos, o fortalecimento do peso do Brasil no cenário internacional até a fuga de acordos que comprometessem o desenvolvimento do país (vigevanie CEPaluni, 2007). O Brasil, portanto, manteve ao longo dos 28 anos deMercosul uma política externa pautada no multilateralismo, procurando evitar o fortalecimento dos Estados Unidos em seu entorno geográfico via integração regional no Cone Sul, ao mesmo tempo em que buscou atingir o status de potência média, colocando-se como um global trader e, posteriormente, um global player (VIGEVANIE CEPALUNI, 2007).

Entretanto, o protagonismo internacional brasileiro vem diminuindo com a crise doméstica. Desde as manifestações populares de 20I3, o Brasil vive uma intensificaçáo das rivalidades entre esquerda e direita, o que culminou no processo de impeachment de Dilma Rousseff entre maio e agosto de 2016. Seu vice, Michel Temer, assumiu com uma agenda liberalizante, marcando a «virada» do país à direita, ou em direção contrária à esquerda (CASARÓES, 20I6; ALMEIDA, 20I7). Nessa agenda, destaca-se em âmbito internacional a ênfase dada a adequação venezuelana à Cláusula Democrática doMercosul e à busca pela concretização do acordo Mercosul-uE.

No caso argentino, os anos 1990 foram marcados pela preferência no relacionamento com os países desenvolvidos, com forte ênfase no comércio e economia. Contudo, com o início da recessão argentina em 1998, o privilégio nas relações com os países desenvolvidos será dado aos Estados Unidos até 200I, por meio da tentativa de se criar uma relação especial com o país. Isso faz com que a Argentina se torne ponto de veto no acordo Mercosul-ue na negociação de 1998. Ao aproximar-se dos Estados Unidos, a "Argentina deixava para trás uma histó- 
ria de confrontaçóes com o país» (BERNAL-MEZA, 1999: 45), aplicando até 1997 uma "política de doublestanding, entre impulsionar exclusivamente oMercosul e impulsioná-lo junto ao projeto norte-americano da ALCA [Área de Livre Comércio das Américas]» (BERNAL-MEZA, I999: 42).

Todavia, o privilégio estadunidense acaba com a mudança de eixo da política externa argentina a partir de 2003 , cuja prioridade passa a ser as relaçóes com o Brasil e o fortalecimento doMercosul em detrimento dos países desenvolvidos (VADELl, 2006). Porém, o privilégio dado aoMercosul centrou-se nas questóes sociais por meio de um «revisionismo crítico dos programas liberalizantes prómercado aplicados nas décadas de I980 e I990» (VADELL, 2006: 196), ocasionando um protecionismo comercial frente à UE e ao Brasil (MACADAR, 2009; VADELL, 2006). Contudo, com a eleição de Mauricio Macri em 20I5, o país também fez uma guinada à direita, voltando sua atençãopara a tentativa de concretizar o acordo Mercosul-eu. Para tanto,Macrivêm adotando políticas de regulação econômica mais abertas que as do governo anterior e se aproximando de polos tradicionais (Estados Unidos e UE) e emergentes de poder (China) (PONTES, 2Or6b).

Brasil e Argentina, além de protagonizarem a criação doMercosul e conflitos intrabloco, para Rolon (20IO), «arrastaram» para o projeto de integração regional o Paraguai (rolon, 20Io). Na visão do autor, o Paraguai pode ser considerado um Estado-tampão entre Brasil e Argentina, tendo sua política externa oscilado em torno dos dois países até o final dos anos 1980, embora se mantivesse alinhada aos Estados Unidos em âmbito sistêmico. Essa política pendular paraguaia é, em certa medida, dificultada pela constituição doMercosul e é «justamente durante os anos de funcionamento deste bloco comercial que mais se expandiu a presença de organizaçóes criminosas regionais e internacionais [no país]» (HIRST, 2005).

A partir do governo de Nicanor Duarte Frutos (2003-2008), o Paraguai procurou melhorar seu relacionamento com os países em desenvolvimento, perseguindo uma política externa que «diversificasse as relaçóes e estreitasse os laços com países que, apesar de distantes geograficamente, poderiam trazer benefícios» (KFURIE LAMAS, 2007: 15). Para tanto, importante conquista paraguaia no período foi o FOCEM, receptor de $48 \%$ dos recursos do fundo. (KFURI Y LAMAS, 2007).

Também é grande beneficiário do FOCEM o outro sócio-menor-fundador do Mercosul, o Uruguai, que privilegiou o bloco a partir dos anos 2000, utilizando-o como ponte para consolidar seu relacionamento com outras naçóes sul-americanas. Junto com o Paraguai, o país demandou «a redução das assimetrias no interior do bloco, 
revelando também seu descontentamento com as negociações que Brasil e Argentina levavam, à margem do Mercosul» (sILVA, 20I2: 7). Todavia, no governo de Tabaré Vasquez (2005-20IO), o Uruguai negociou um tratado de livre comércio (TLC) com os Estados Unidos, que se concretizado causaria sua denuncia ao acordo do Mercosul.

Mas, apesardo descontentamento uruguaio com as assimetrias do bloco, não houve consenso doméstico para o TLC entre Uruguai e Estados Unidos (SILVA, 20I2). O que não significou o fim da diversificação de parceiros: foram firmados convênios com China, Cuba, Rússia e Venezuela (SILVA, 20I2). Em 20ı6, o governo uruguaio assinou acordos de cooperação em diversas áreas com a China e tentou iniciar as negociaçôes para a celebração de um TLC para 2018 com o país asiático (PONTES, 20i6a), que não foi concretizado.

Por sua vez, a Venezuela, membro doMercosul desde 20I2, opôs-se por muito tempo a integração regional, isolando-se da região e privilegiando as relaçôes com os Estados Unidos. Tal posição é alterada nos anos 1990 quando a política externa passa a privilegiar os eixos Sul e Leste, ação intensificada nos anos 2000 (LOPES E HITNER, 2009). Nesse momento, «a integração passa a ser vista, então, como um mecanismo relevante, mas com um papel diferenciado, já que o objetivo não é mais substituir em escala regional as importaçôes, mas permitir ao país uma inserção no cenário internacional» (LOPES E HITNER, 2009: I66).

Durante o governo de Hugo Chávez (1999-2013) o destaque foi dado à integração social, visando à consolidação de um bloco do Sul e a efetivaçáo de um mundo pluripolar. $\mathrm{O}$ que acarretou um aumento nas tensóes do país com os Estados Unidos e a aproximação dos países doMercosul e da China (LOPES E HITNER, 2009). Entretanto, com o governo de Nicolás Maduro (2013-), a essa tensão com os Estados Unidos se somaram às diversas manifestaçóes populares e as crises política e econômica domésticas, expandindo a tensãoao próprio Mercosul (PONTES, 2016c). Com as mudanças políticas na Argentina e Brasil citadas anteriormente, iniciaram-se questionamentos acerca da permanênciada Venezuela no Mercosul, os quais culminaramna suspensão dos direitos e obrigaçôes do país por duas vezes:em dezembro de 20ı6, devido à não adequação às normas comerciais seguidas pelo bloco e em agosto de 20I7, devido ao não respeito à cláusula democrática - suspensão que ainda se mantém (MARCHAO, 20I7).

Com os elementos dessa breve exposição da evolução doMercosul e das políticas externas dos membros bloco em mente, passaremos para a análise dos resultados sobre a percepção da sociedade mercosulina em relação à percepção sobre política externa. 


\section{PERCEPÇÕES DA OPINIÃO PÚBLICA NO MERCOSULSOBRE POLÍTICA EXTERNA}

Para delinearmos o pensamento da sociedade mercosulina em relação às direçôes dos países do bloco e, consequentemente, do próprio bloco, analisamos os dados dos surveys do Latinobarómetro ${ }^{10}$ de 20IO, 20II, 2013, 20I5, 2016 e 2017. Em todos os anos foram entrevistados I2OO argentinos, I2O4 brasileiros, I200 paraguaios, I2OO uruguaios e I200 venezuelanos sobre o «desarrollo de la democracia, laeconomía y lasociedadensu conjunto, usando indicadores de opinión pública que midenactitudes, valores y comportamientos» (LATINOBARÓMETRO, 20I8a), além de questóes socioeconômicas. Dada à quantidade de perguntas, selecionamos apenas as que se relacionam com nosso objeto (a percepção sobre política externa e a inserção do país no mundo) e as reagrupamos em dois blocos, sendo A) opiniấo sobre polos de poder; е в) disposição para a integração do país com o mundo. A seguir estão descritos os resultados encontrados.

\section{Opinião sobre polos de poder}

Como visto na seção II, as políticas externas dos países doMercosul tiveram dois eixos de atuação vistos como antagônicos na literatura sobre política externa latino-americana entre os anos 1990 e 2000: a aproximaçáo regional sul-americana e a aproximação com os países desenvolvidos, principalmente, Estados Unidos e EU. Todavia, a partir dos anos 2000 emergem novos polos de poder, como a China ${ }^{11}$. Dessa forma, a percepção da opinião pública mercosulina sobre esses polos de poder é aspecto importante para gerar legitimidade às políticas externas adotadas pelos Estados-membros.

10] $O$ Latinobarómetro é «um estudo de opinião pública que aplica anualmente cerca de 20.000 entrevistas em 18 países da América Latina [Argentina, Bolívia, Brasil, Chile, Colômbia, Costa Rica, República Dominicana, Equador, El Salvador, Guatemala, Honduras, México, Nicarágua, Panamá, Paraguai, Peru, Uruguai e Venezuela]. A CorporaciónLatinobarómetro é uma ONG sem fins lucrativos com sede em Santiago do Chile, única responsável pela produção e publicação de dados» (LATINOBARÓMETRO, 2018b, tradução nossa). Todavia, para nosso estudo selecionamos somente os dados dos cinco países membros do Mercosul.

11] Sobre o assunto ver: LEÃO, PINTO e ACIOLY (2011). 
TABELA 1:

OPINIÃO MERCOSULINA SOBRE OS ESTADOS UNIDOS (EM PORCENTAGEM POR ANO)

\begin{tabular}{|c|c|c|c|c|c|c|c|}
\hline & & ARGENTINA & BRASIL & PARAGUAI & URUGUAI & VENEZUELA & TOTAL \\
\hline \multirow{2}{*}{ MUITO BOA/BOA } & 2010 & 59,4 & 72,5 & 65,8 & 66,1 & 63,4 & 65,4 \\
& 2011 & 53,6 & 73,8 & 79,3 & 52,8 & 56,7 & 63,2 \\
& 2013 & 50,3 & 73,8 & 77,8 & 59,3 & 55,9 & 63,4 \\
& 2015 & 50,3 & 65,4 & 49,4 & 60,3 & 51,8 & 55,5 \\
& 2016 & 56,8 & 74,4 & 79,6 & 63,2 & 64,9 & 67,6 \\
& 2017 & 48,5 & 67,1 & 63,0 & 53,8 & 59,4 & 58,4 \\
& & & & & & & \\
RUIM/MUITO RUIM & 2010 & 33,5 & 17,2 & 16,3 & 20,2 & 28,6 & 23,2 \\
& 2011 & 40,4 & 19,0 & 12,0 & 33,5 & 36,1 & 28,2 \\
& 2013 & 35,8 & 15,0 & 10,6 & 23,7 & 34,6 & 23,9 \\
& 2015 & 34,2 & 16,4 & 11,9 & 22,2 & 39,4 & 24,7 \\
& 2016 & 29,8 & 12,5 & 6,9 & 19,8 & 30,3 & 19,8 \\
& 2017 & 41,1 & 17,4 & 10,5 & 34,4 & 35,7 & 27,8 \\
& & & & & & & \\
& 2010 & 6,3 & 9,5 & 17,0 & 12,3 & 5,4 & 10,1 \\
& 2011 & 5,3 & 6,4 & 7,0 & 11,8 & 5,4 & 7,2 \\
& 2013 & 13,5 & 9,2 & 11,1 & 13,6 & 8,7 & 11,2 \\
& 2015 & 14,8 & 17,3 & 34,1 & 15,8 & 7,9 & 18,0 \\
& 2016 & 13,6 & 11,0 & 10,3 & 15,5 & 2,7 & 10,6 \\
& 2017 & 10,4 & 15,4 & 26,5 & 11,8 & 4,9 & 13,8 \\
\hline$\tilde{N}$ 0 SABE & & & & & & &
\end{tabular}

FONTE: elaboração própria com base em LATINOBARÓMETRO, 2018c. 
TABELA 2.

OPINIÃO MERCOSULINA SOBRE A UNIÃO EUROPEIA (EM PORCENTAGEM POR ANO)

\begin{tabular}{|c|c|c|c|c|c|c|c|}
\hline & & ARGENTINA & BRASIL & PARAGUAI & URUGUAI & VENEZUELA & TOTAL \\
\hline \multirow[t]{6}{*}{ MUITO BOA/BOA } & 2010 & 61,8 & 59,7 & 57,2 & 64,8 & 63,8 & 61,4 \\
\hline & 2011 & 57,2 & 63,5 & 69,5 & 55,4 & 63,3 & 61,8 \\
\hline & 2013 & 44,1 & 48,9 & 60,3 & 47,9 & 42,8 & 48,8 \\
\hline & 2015 & 46,6 & 43,6 & 33,5 & 48,4 & 49,2 & 42,4 \\
\hline & 2016 & 52,0 & 60,0 & 65,2 & 53,8 & 50,9 & 56,4 \\
\hline & 2017 & 56,8 & 54,4 & 52,5 & 67,9 & 61,3 & 58,9 \\
\hline \multirow[t]{6}{*}{ RUIM/MUITO RUIM } & 2010 & 18,7 & 15,0 & 9,6 & 10,4 & 17,0 & 14,1 \\
\hline & 2011 & 25,3 & 17,1 & 17,1 & 18,8 & 21,4 & 18,6 \\
\hline & 2013 & 27,4 & 23,4 & 7,6 & 18,0 & 32,7 & 21,8 \\
\hline & 2015 & 20,4 & 13,0 & 9,9 & 16,8 & 31,4 & 18,3 \\
\hline & 2016 & 19,0 & 14,2 & 7,9 & 12,5 & 30,3 & 16,8 \\
\hline & 2017 & 16,2 & 12,3 & 5,6 & 8,6 & 19,5 & 12,2 \\
\hline \multirow[t]{6}{*}{ NÃO SABE } & 2010 & 19,0 & 23,8 & 32,2 & 22,9 & 16,3 & 22,8 \\
\hline & 2011 & 16,3 & 17,4 & 17,8 & 22,5 & 13,3 & 17,4 \\
\hline & 2013 & 27,8 & 25,0 & 31,3 & 29,9 & 23,0 & 27,4 \\
\hline & 2015 & 32,2 & 42,6 & 52,1 & 32,7 & 27,3 & 37,4 \\
\hline & 2016 & 27,7 & 22,2 & 20,3 & 31,8 & 9,5 & 22,3 \\
\hline & 2017 & 27,1 & 33,3 & 41,9 & 23,5 & 19,2 & 29,0 \\
\hline
\end{tabular}

FONTE: elaboração própria com base em LATINOBARÓMETRO, 2018c. 
TABELA 3.

OPINIÃO MERCOSULINA SOBRE A CHINA (EM PORCENTAGEM POR ANO)

\begin{tabular}{|l|c|c|c|c|c|c|c|}
\hline & & ARGENTINA & BRASIL & PARAGUAI & URUGUAI & VENEZUELA & TOTAL \\
\hline \multirow{2}{*}{ MUITO BOA/BOA } & 2010 & 58,2 & 61,0 & 49,6 & 52,3 & 77,5 & 59,2 \\
& 2011 & 60,9 & 59,2 & 75,3 & 50,0 & 75,5 & 64,2 \\
& 2013 & 54,3 & 56,6 & 58,5 & 51,8 & 66,8 & 57,6 \\
& 2015 & 50,2 & 48,3 & 29,8 & 42,9 & 59,6 & 46,2 \\
& 2016 & 49,2 & 60,0 & 64,3 & 50,0 & 62,8 & 57,3 \\
& 2017 & 59,0 & 54,5 & 47,7 & 58,5 & 69,2 & 57,8 \\
& & & & & & & \\
RUIM/MUITO RUIMI & 2010 & 19,6 & 20,0 & 15,2 & 14,8 & 11,2 & 16,2 \\
& 2011 & 22,1 & 27,2 & 9,5 & 20,9 & 15,2 & 19,0 \\
& 2013 & 21,7 & 24,4 & 12,1 & 17,7 & 20,6 & 19,3 \\
& 2015 & 21,6 & 21,0 & 19,8 & 23,1 & 29,7 & 23,0 \\
& 2016 & 24,3 & 22,9 & 13,1 & 14,5 & 27,9 & 21,4 \\
& 2017 & 19,8 & 19,1 & 8,8 & 17,2 & 21,8 & 17,4 \\
& & & & & & & \\
& 2010 & 21,8 & 17,9 & 34,1 & 29,8 & 9,3 & 22,6 \\
& 2011 & 16,3 & 12,1 & 12,7 & 25,8 & 7,9 & 15,0 \\
& 2013 & 23,3 & 16,9 & 28,1 & 26,8 & 11,5 & 21,3 \\
& 2015 & 27,3 & 29,7 & 46,2 & 31,9 & 10,5 & 29,1 \\
& 2016 & 25,3 & 14,5 & 16,8 & 29,3 & 5,9 & 18,4 \\
& 2017 & 21,2 & 26,4 & 43,5 & 24,4 & 9,0 & 24,8 \\
\hline
\end{tabular}

FONTE: elaboração própria com base em LATINOBARÓMETRO, 2018c.

Observando as tabelas I, 2 e 3, vemos que a maioria dos entrevistados, em especial os paraguaios em 20II, 2013 e 20I6, possui uma boa opiniáo sobre os Estados Unidos, apesar das altas porcentagens (entre 30 e 40\%) argentina e venezuelana de opinião ruim. Percebemos que a Argentina «ensaiava» uma diminuição na opiniâo negativa sobre os Estados Unidos entre 2011 e 2016 (caindo de 40,4\% a 29,8\%), porém, em 2017 essa opiniáo negativa volta a subir (indo para os 4I,I\%).

Da mesma forma, as respostas com opinião positiva foram a maioria com relação à União Europeia, também puxadas pelos paraguaios em 20II, 2013 e 2016 e pelos uruguaios em 20I7. Apesar de, em nenhum ano, a percepção positiva sobre a UE ultrapassar os 70\%, a percepçáo negativa conta com porcentagens mais baixas que os Estados Unidos: enquanto a percepção negativa sobre os Estados Unidos 
oscila entre I9, $8 \%$ e $28,2 \%$, a percepção negativa sobre a UE oscila entre I2,I\% e 21,8\%.Em contraposição, a opção «não sabe opinar» possui porcentagens mais altas para a UE que para os Estados Unidos, chegando até a ultrapassar os 50\% entre os paraguaios em 2015 .

Já com relação à China, mantêm-se as opiniōes positivas como maioria, puxadas pelos venezuelanos (acima dos 60\% em todos os anos analisados). Entretanto, também se notam porcentagens mais altas da opção «náo sabe opinar» para a China que para os Estados Unidos, chegando até a 46\% em 2015 e a $43 \%$ em 2017 entre os paraguaios. Curiosamente, $75 \%$ dos paraguaios percebiam a China de forma positiva em 2013 .

Nessa perspectiva, por meio das tabelas I, 2 e 3 percebemos índices elevados da resposta «não sabe opinar» a depender do polo de poder citado (Estados Unidos, UE ou China) e da nacionalidade do respondente. Todavia, apesar das altas porcentagens de «não sabe opinar» nos pontos levantados acima, a porcentagem de pessoas que opinaram ainda ultrapassa a porcentagem dos «desinformados». Com isso, podemos afirmar que a opiniáo pública não é totalmente bem informada.

Ainda sobre os polos de poder cabe destacar que em 20II, o Latinobarómetro apresentou as seguintes questóes: «quanto os Estados Unidos [e a China] ajudam a economia [de seu país] com seu comércio e investimento?» e «quanto os Estados Unidos [e a China] provêm ajuda humanitária [a seu país]?». 
GRÁFICO 1:

OPINIÃO MERCOSULINA SOBRE AJUDA ECONÔMICA POR MEIO DE COMÉRCIO E INVESTIMENTOS

DE CHINA E ESTADOS UNIDOS EM 2011 (EM PORCENTAGEM)

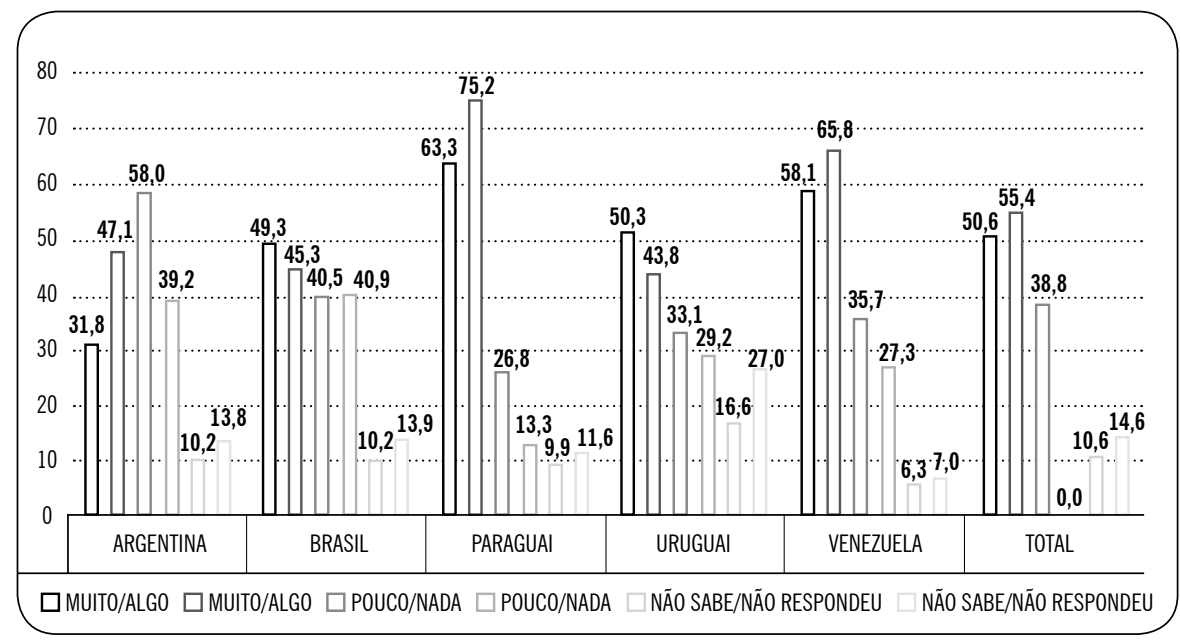

FONTE: elaboração própria com base em LATINOBARÓMETRO, 2011.

GRÁFICO 2:

OPINIÃO MERCOSULINA SOBRE AJUDA HUMANITÁRIA DE CHINA E ESTADOS UNIDOS EM 2011 (EM PORCENTAGEM)

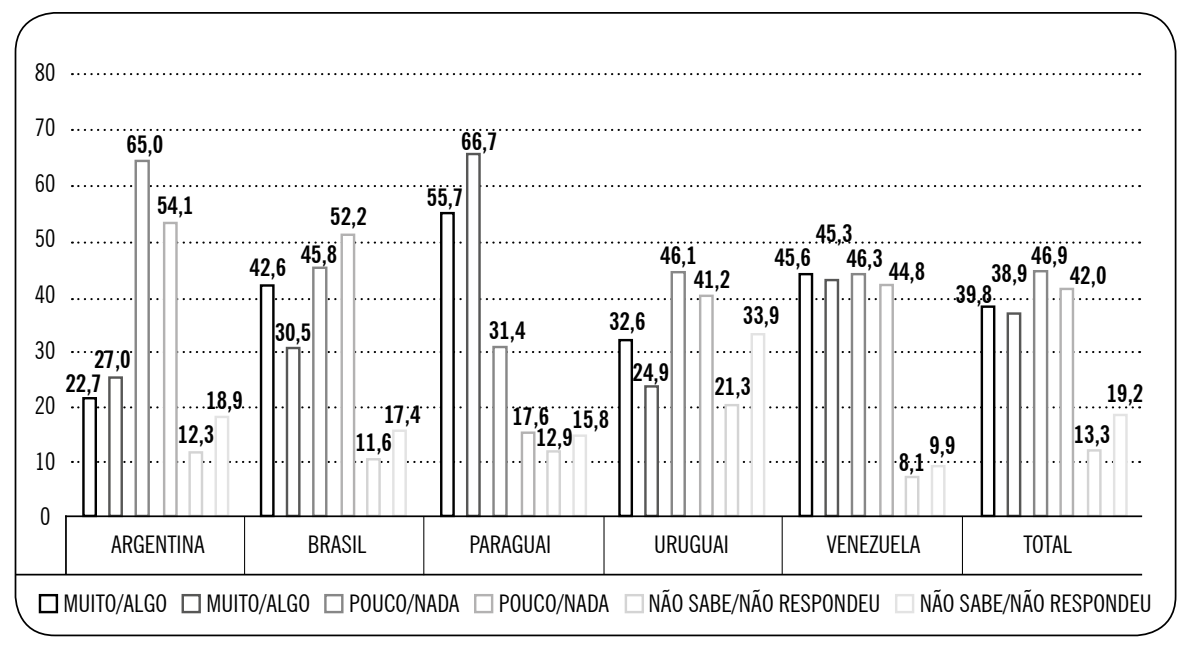

FONTE: elaboração própria com base em LATINOBARÓMETRO, 2011. 
Pelos gráficos i e 2, percebe-se que quando o tema é ajuda na economia por meio de comércio e investimentos, os brasileiros não percebem diferenças entre a atuação chinesa (em torno de $40 \%$ para ajuda muito/algo e $40 \%$ para ajuda pouco/nada) e a estadunidense (49,26\% para ajuda muito/algo e $45,76 \%$ para ajuda pouco/nada). Já quando o tema é ajuda humanitária são os venezuelanos que não percebem diferenças na atuação dos dois polos de poder em questáo (em torno de $45 \%$ para os Estados Unidos ajudarem muito/algo e pouco/nada e $46,33 \%$ para a China ajudar muito/algo e 44,83\% ajudar pouco/nada).

De forma geral, sobre a ajuda na economia por meio de comércio e investimentos, os argentinos, paraguaios e venezuelanos percebem uma maior contribuiçáo chinesa. Por outro lado, argentinos, brasileiros e uruguaios atribuem pouca/nenhuma ajuda humanitária aos dois polos, enquanto, paraguaios percebem ajuda de ambos os polos, sendo maior a ajuda humanitária chinesa.

Portanto, ao analisar a opiniáo sobre os polos tradicionais e os novos polos de poder, percebemos uma proximidade da opinião da população com as açóes de política externa dos países no período em questão: desde o início do século XXI, os membros do Mercosul vêm diversificando seus parceiros, mas mantendo relações com parceiros tradicionais com foco em investimentos e comércio e não em ajuda humanitária.

\section{Disposição para a integração do país com o mundo}

Como visto na seção II, cada membro do Mercosul perseguiu ao longo dos anos uma estratégia de integração com o mundo, seja privilegiando o eixo regional ou o eixo global ou privilegiando relaçóes econômicas ou políticas e sociais. Dessa forma, o Latinobarómetro apurou como tais estratégias impactaram na vida dos cidadãos, se positiva ou negativamente, segundo a visão dos entrevistados.

Primeiramente, destaca-se a posição da sociedade mercosulina sobre integração econômica e cooperação política entre os países latino-americanos, aspecto de relevância devido aos caminhos seguidos pelo Mercosul e seus membros ao longo dos 28 anos de existência do bloco, como abordado na seção II. 
TABELA 4:

POSIÇÃO SOBRE INTEGRAÇÃO ECONÔMICA INTRA-AMÉRICA LATINA (EM PORCENTAGEM)

\begin{tabular}{|l|c|c|c|c|c|c|c|}
\hline & & ARGENTINA & BRASIL & PARAGUAI & URUGUAI & VENEZUELA & TOTAL \\
\hline MUITO FAVORÁVEL/ & 2010 & 90,0 & 66,5 & 72,9 & 82,4 & 78,2 & 78,0 \\
ALGO FAVORÁVEL & 2016 & 81,3 & 65,8 & 89,0 & 86,8 & 85,4 & 81,5 \\
& & & & & & & \\
MUITO CONTRÁRI0/ & 2010 & 3,5 & 14,5 & 9,8 & 6,9 & 15,0 & 10,0 \\
ALGO CONTRÁRI0 & 2016 & 15,3 & 21,7 & 4,9 & 9,2 & 11,6 & 12,5 \\
& & & & & & & \\
NÃO SABE/ & 2010 & 6,3 & 18,4 & 16,9 & 9,8 & 5,8 & 11,5 \\
NÃO RESPONDEU & 2016 & 4,3 & 12,5 & 6,1 & 4,0 & 3,0 & 6,0 \\
\hline
\end{tabular}

FONTE: elaboração própria com base em LATINOBARÓMETRO, 2018c.

TABELA 5:

POSIÇÃO SOBRE COOPERAÇÃO POLITICA INTRA-AMÉRICA LATINA (EM PORCENTAGEM)

\begin{tabular}{|l|c|c|c|c|c|c|c|}
\hline & & ARGENTINA & BRASIL & PARAGUAI & URUGUAI & VENEZUELA & TOTAL \\
\hline MUITO FAVORÁVEL/ & 2010 & 84,4 & 62,6 & 61,6 & 64,3 & 69,8 & 68,5 \\
ALGO FAVORÁVEL & 2016 & 72,3 & 55,3 & 70,3 & 67,5 & 76,4 & 68,4 \\
& & & & & & & \\
MUITO CONTRÁRI0/ & 2010 & 6,4 & 17,6 & 17,2 & 21,3 & 22,6 & 17,0 \\
ALGO CONTRÁRI0 & 2016 & 20,8 & 32,2 & 20,9 & 25,3 & 19,7 & 23,7 \\
& & & & & & & \\
NÃO SABE/ & 2010 & 8,8 & 18,9 & 20,4 & 13,3 & 6,2 & 13,5 \\
NÃO RESPONDEU & 2016 & 6,9 & 12,6 & 8,8 & 7,3 & 3,9 & 7,9 \\
\hline
\end{tabular}

FONTE: elaboração própria com base em LATINOBARÓMETRO, 2018c.

Ao analisar as tabelas 4 e 5 , é perceptível um maior apoio à integração econômica que à cooperação política, conquanto o apoio à cooperação política seja acima dos 50\% nos dois anos analisados e em todos os países. Com relação à integração econômica, Argentina e Brasil são os países em que a porcentagem de entrevistados favoráveis diminui de 2010 a 2016, sendo uma queda maior na Argentina e quase 
imperceptível no Brasil. Apesar do aumento geral das posições contrárias à integração econômica, no Paraguai há uma queda entre 2010 e 2016 nessas posiçôes.

Já sobre a cooperação política, a porcentagem geral se mantém estável com tendência de queda, devido às posiçóes argentinas e brasileiras: em ambos os países o apoio cai consideravelmente entre 2010 e 20I6. As posiçōes contrárias aumentam em todos os países selecionados, exceto na Venezuela.

O Latinobarómetro também apurou como as estratégias de inserção internacional dos países impactaram na vida dos cidadãos, se positiva ou negativamente, segundo a visão dos entrevistados.

Pelos dados vemos que, no conjunto dos membros do Mercosul, os itens «Emprego e trabalho", «Investimento externo», «Exportaçôes do país» e "Acesso à tecnologia» possuem avaliaçóes positivas muito fortes; ocorrendo o inverso com o item «Seguridade social». O item «Sua situação pessoal/familiar» possui avaliaçôes positivas e negativas muito próximas. Ressalta-se ainda que na análise individual dos países, a Venezuela é o único dos membros que considera todos os itens, com exceção do "Acesso à tecnologia», como frutos negativos da relação do país com o mundo.

Todavia, mesmo com a posição favorável à integração regional, quando questionados sobre a disposição a pagar impostos mais altos para que o país financie obras de infraestrutura visando à integração global, em 20I5, 31,9\% dos entrevistados nos cinco países responderam «nada de aumento» e apenas 3,9\% aceitariam «todo o aumento necessário». Em 20I6, as cifras não se alteraram muito: 3I,6\% não desejam «nada de aumento» e 5,9\% aceitariam «todo o aumento necessário».

Cabe destacar que, em 2015, Brasil e Uruguai possuíam as taxas de rejeição mais altas $(44,6 \%$ dos brasileiros e $43,2 \%$ dos uruguaios responderam «nada de aumento»), sendo o Brasil substituído pela Argentina em 2016 (4I,4\% dos argentinos e $4 \mathrm{I}, 5 \%$ dos uruguaios responderam «nada de aumento» contra $34,5 \%$ dos brasileiros e $20 \%$ de paraguaios e venezuelanos). 
TABELA 6:

IMPACTO DA ESTRATÉGIA INTERNACIONAL DO PAÍS NOS ÚLTIMOS 5 ANOS SOBRE DIVERSOS TEMAS (EM PORCENTAGEM)

\begin{tabular}{|c|c|c|c|c|c|c|c|}
\hline & & ARGENTINA & BRASIL & PARAGUAI & URUGUAI & VENEZUUELA & TOTAL \\
\hline EMPREGO & POSITIVA & 41,8 & 48,1 & 46,5 & 73,3 & 33,9 & 48,7 \\
\hline \multirow[t]{3}{*}{ E TRABALHO } & NEGATIVA & 40,3 & 29,1 & 28,1 & 12,3 & 56,0 & 33,1 \\
\hline & NÃO SABE/ & & & & & & \\
\hline & NÃO RESPONDEU & 17,8 & 22,8 & 25,9 & 13,9 & 10,1 & 18,2 \\
\hline \multirow{4}{*}{$\begin{array}{l}\text { INVESTIMENTO } \\
\text { EXTERNO NO PAÍS }\end{array}$} & POSITIVA & 46,3 & 48,9 & 59,5 & 77,8 & 35,2 & 53,5 \\
\hline & NEGATIVA & 33,3 & 25,0 & 14,4 & 8,8 & 55,3 & 27,3 \\
\hline & NÃO SABE/ & & & & & & \\
\hline & NÃO RESPONDEU & 20,5 & 26,1 & 26,1 & 13,4 & 9,6 & 19,2 \\
\hline \multirow{4}{*}{$\begin{array}{l}\text { EXPORTAÇÕES } \\
\text { DE SEU PAÍS }\end{array}$} & POSITIVA & 48,6 & 52,4 & 60,3 & 78,9 & 35,2 & 55,0 \\
\hline & NEGATIVA & 29,7 & 20,3 & 12,2 & 6,8 & 55,2 & 24,8 \\
\hline & NÃO SABE/ & & & & & & \\
\hline & NÃO RESPONDEU & 21,8 & 27,4 & 27,6 & 14,3 & 9,7 & 20,2 \\
\hline \multirow{4}{*}{$\begin{array}{l}\text { ACESSO À } \\
\text { TECNOLOGIA } \\
\text { POR SEU PAÍS }\end{array}$} & POSITIVA & 66,0 & 62,4 & 62,3 & 84,5 & 52,5 & 65,5 \\
\hline & NEGATIVA & 18,9 & 14,4 & 12,3 & 3,3 & 40,0 & 17,7 \\
\hline & NÃO SABE/ & & & & & & \\
\hline & NÃO RESPONDEU & 15,1 & 23,2 & 24,4 & 12,3 & 7,5 & 16,8 \\
\hline \multirow{4}{*}{$\begin{array}{l}\text { SEGURIDADE } \\
\text { SOCIAL }\end{array}$} & POSITIVA & 20,9 & 28,4 & 26,5 & 30,0 & 23,2 & 25,8 \\
\hline & NEGATIVA & 58,4 & 46,2 & 42,3 & 46,1 & 67,7 & 52,1 \\
\hline & NÃO SABE/ & & & & & & \\
\hline & NÃO RESPONDEU & 20,7 & 25,4 & 31,2 & 23,9 & 9,2 & 22,1 \\
\hline \multirow{4}{*}{$\begin{array}{l}\text { SUA SITUAÇÃO } \\
\text { PESSOAL/FAMILIAR }\end{array}$} & POSITIVA & 36,3 & 38,7 & 42,1 & 52,2 & 29,6 & 39,8 \\
\hline & NEGATIVA & 36,7 & 33,0 & 29,1 & 18,8 & 58,3 & 35,1 \\
\hline & NÃO SABE/ & & & & & & \\
\hline & NÃO RESPONDEU & 27,0 & 28,3 & 28 & 29,1 & 12,2 & 25,1 \\
\hline
\end{tabular}

FONTE: elaboração própria com base em LATINOBARÓMETRO, 2018c. 
GRÁFICO 3:

ESCALA DE DISPOSIÇÃO PARA AUMENTO DE IMPOSTOS EM FAVOR DA INTEGRAÇÃO DO PAÍS COM O MUNDO, $2015^{12}$.

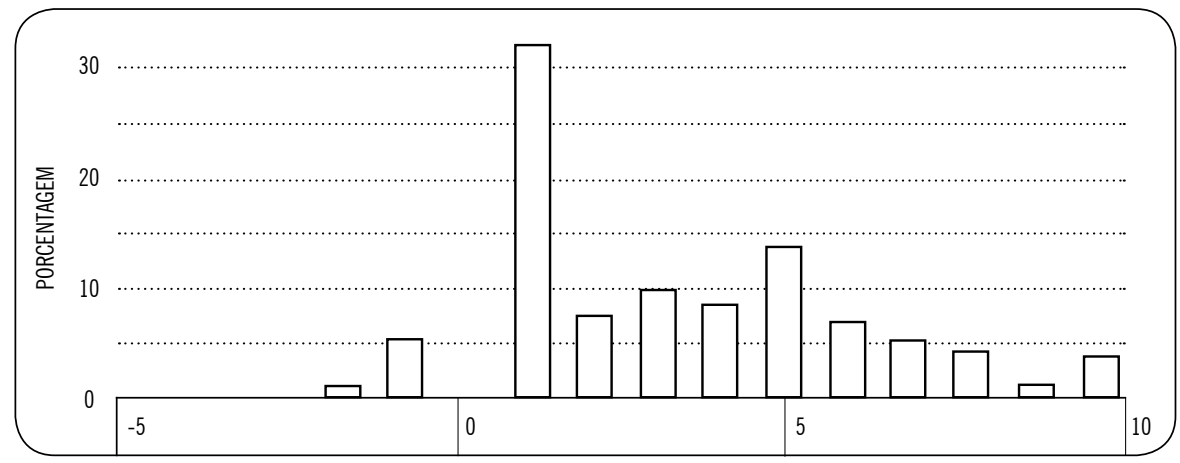

FONTE: elaboração própria com base em LATINOBARÓMETRO, 2015.

GRÁFICO 4:

ESCALA DE DISPOSIÇÃO PARA AUMENTO DE IMPOSTOS EM FAVOR DA INTEGRAÇÃO DO PAÍS COM O MUNDO, $2016{ }^{13}$.

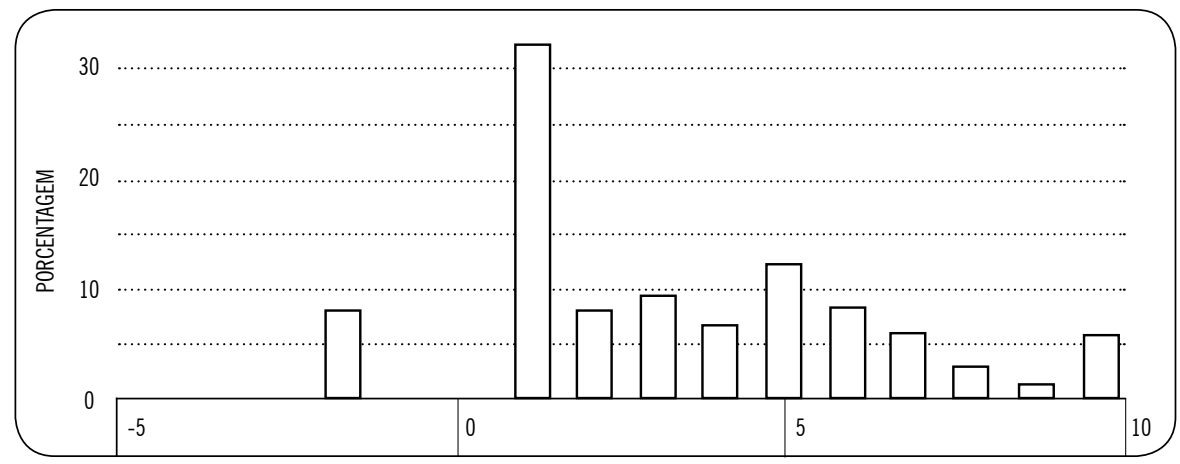

FONTE: elaboração própria com base em LATINOBARÓMETRO, 2016.

12] A pergunta utilizou uma escala de $1,-$ «nada de aumento-, até 10, -«todo o aumento necessário»-. As colunas presentes antes do zero referem-se às respostas «não sabe» e "não opinou».

13] A pergunta utilizou uma escala de 1 -«nada de aumento-, até 10, -«todo o aumento necessário»-. As colunas presentes antes do zero referem-se às respostas «não sabe» e «não opinou». 
Ou seja, os mercosulinos estão dispostos a se integrar economicamente em âmbito regional, mas não globalmente, se isso significar aumento de impostos. Portanto, extrai-se dos dados apresentados nas subseçóes А е в que os polos tradicionais de poder, Estados Unidos e União Europeia, são vistos positivamente por boa parte da população mercosulina, assim como novos polos, caso da China, que aparece com avaliações positivas próximas as dos Estados Unidos ou até ultrapassando-o. Desse modo, as oscilaçóes individuais nas opiniōes das populaçôes de cada membro em relação aos Estados Unidos, UE e China parecem refletir as desavenças ou boas relações no plano das relaçóes internacionais dos membros. Reflexo que também é percebido na análise sobre ajuda econômica ou humanitária de Estados Unidos ou China aos países doMercosul (em países com ressalvas ao apoio econômico dos Estados Unidos os cidadãos percebem a China como alternativa melhor).

Fica claro ainda a preferência maior entre os mercosulinos pela integração econômica e não pela cooperação política de seus países com a América Latina, apesar das oscilaçôes individuais de cada país do bloco. Todavia, mesmo existindo uma percepção de que a integração traz benefícios, existe uma incerteza quanto aos benefícios pessoais e sobre a seguridade social que a atuação internacional dos países membros pode acarretar, o que se reflete nas altas taxas de indisposição a pagar mais impostos visando à integração do país com o mundo.

\section{OS POSSÍVEIS CAMINHOS DOMERCOSUL}

Pela análise dos dados dos surveysdo Latinobarómetro é possível afirmar que a sociedade mercosulina vê positivamente as novas tendências mundiais de emergência de novos polos, apesar de manter sua impressão positiva sobre os antigos polos (como exposto nas tabelas I, 2 e 3). Além disso, percebe a integração regional como positiva (tabelas 4 e 5 ), mas não está disposta a investir seus recursos nesses projetos (gráficos 3 e 4).

Com relação ao consenso de Almond-Lippmann, com nosso estudo, não podemos confirmar que a opinião pública sobre política internacional é altamente volátil e que essa opinião pública tem impacto limitado sobre os que conduzem a política externa, dado suas preferências refletirem no ou serem reflexos do caminho traçado por seus países. O que, entretanto, não faz parte do escopo desse trabalho, cujo objetivo foi verificar para quais direçôes e caminhos a opinião pública dos cidadãos 
dos países doMercosul apontam. Do mesmo modo, não podemos afirmar que as políticas externas dos países membros do Mercosul e do próprio bloco sofreram demandas da sociedade, pois isso demandaria um estudo separado de cada país.

Todavia, percebemos que essa sociedade mercosulina aponta para a diversificação de parceiros (vemos isso nos bons índices alcançados pela China na tabela 3) e para um fortalecimento da integração regional via economia (já que segundo a tabela 4, houve um aumento de 2010 para 2016 entre os entrevistados dos países doMercosul favoráveis a esse tipo de integraçáo, alcançando os 81\% de apoio). O que nos mostra uma proximidade entre a opiniáo pública e as açóes tomadas pelos membros do bloco, principalmente a partir de 2015 .

Da mesma forma, percebemos uma oposição entre a racionalidade de que a integração regional é positiva versus o sentimento de que não querer contribuir financeiramente (via aumento de impostos) com a melhora de infraestrutura do país para a integração global. Isso pode ser explicado como um ressentimento em relação às políticas neoliberais dos anos 1990 ou até mesmo ao não-avanço da Iniciativa para a Integração da Infra-estrutura Regional Sul-americana (IIRSA) nos anos 2000, mas, novamente, não é nosso objetivo nos aprofundar nesse tema aqui.

Nessa perspectiva, pode-se afirmar que parte de nossa hipótese está correta, já que a opinião pública mercosulina nos anos 2010 mostra-se favorável à China, a representante de um novo polo de poder. Contudo, os dados analisados indicam que essa sociedade não é tão fechada ao livre-comércio quanto se pressupunha inicialmente, pois os entrevistados acreditam que a cooperação comercial e financeira entre países é melhor para a integração que a cooperação política. Apesar da preocupação sobre esses custos ser verdadeira.

\section{Referências bibliográficas}

ALMEIDA, MARIA HERMÍNIA TAVARES (2017): «Sob a nevoa da crise», Trabalhos em Curso, 2, Ed. Panguila. ARBILLA, JOSÉ MARIA (2000): «Arranjos Institucionais e Mudança Conceitual nas Políticas Externas Ar-

gentina e Brasileira (1989-1994)», em: Contexto Internacional, $\mathrm{n}^{\circ} 22$, vol. 2.

BERNAL-MEZA, RAÚL(1999): «Políticas exteriores comparadas de Argentina e Brasil rumo ao Mer- 
cosul», em: RevistaBrasileira dePolíticalnternacional, $\mathrm{n}^{\circ}$ 42, vol. 2.

CASARÕES, GUILHERME STOLE PAIXÃO (2016): «A Política Externa interina e os riscos à integração regional», em: Conjuntura Austral, n 37, vol. 7. CERVO, AMADO LUIZ; LESSA E ANTÔNIO CARLOS (2014): "O declínio: inserção internacional do Brasil (2011-2014)», em: RevistaBrasileira de Políticalnternacional, $\mathrm{n}^{\circ}$ 57, vol. 2.

CORAZZA, GENTIL E HERRERA, RÉMY (2006): «O «regionalismo aberto> da CEPAL e a inserção da América Latina na globalização», em: Ensaios FEE, $n^{\circ} 27$, vol. 1 .

DECRETO No 350, (1991): Promulga o Tratado para a Constituição de um Mercado Comum entre a República Argentina, a República Federativa do Brasil, a República do Paraguai e a República Oriental do Uruguai (Tratado Mercosul), Diário Oficial da União, 21 de novembro de 1991, Brasília. GAZZOLA, ANA ELISA THOMAZELLA E ARAÚJO, ANDRÉ LEITE (2018): «Bolívia: o processo de tornar-se membro pleno do Mercosul», em: $42^{\circ}$ Encontro Anual da ANPOCS, Caxambu, 22 a 26 outubro.

GERALDELLO, CAMILLA SILVA (2014): « «Autonomias» na Política Externa Brasileira: exercícios da Teoria da Autonomia?», em: Revista de Estudos Internacionais, $\mathrm{n}^{\circ} 5$, vol. 2 .

GUILHERME, ROSILAINE CORADINI, REISE CARLOS NELSON (2018): «Plano Estratégico de Ação Social do MERCOSUL: a transferência de renda em contexto de ofensiva neoliberal», em: Revista Katálysis, n 21 , vol. 1.

HIRST, MONICA (1988): «Contexto e estratégia do Programa de Integração Argentina-Brasil», em: Revista de Economia Política, $\mathrm{n}^{\circ}$ 8, vol.3. HIRST, MONICA (2005): «As relações Brasil-Paraguai: baixos incentivos no latu e strictu sensu», em: Política Externa, no 14, vol. 3.

KFURI, REGINA E LAMAS, BARBARA (2007): «Entre oMer- cosul e os Estados Unidos: as relações externas do Paraguai», em: $31^{\circ}$ Encontro Anual da ANPOCS. Caxambu, 22 a 26 outubro.

HOLSTI, OLER (1992): «Public Opinion and Foreign Policy: Challenges to the Almond-Lippmann Consensus Mershon Series: Research Programs and Debates», em: International Studies Quarterly, $n^{\circ} 36$, vol. 4.

LATINOBARÓMETRO (2011): Latinobarómetro, Banco de datos. Recuperado a partir de http://www. latinobarometro.org/latContents.jsp (última entrada: 26/06/2019).

LATINOBARÓMETRO (2015): Latinobarómetro, Banco de datos. Recuperado a partir de http://www. latinobarometro.org/latContents.jsp (última entrada: 26/06/2019).

LATINOBARÓMETRO (2016): Latinobarómetro, Banco de datos. Recuperado a partir de http://www. latinobarometro.org/latContents.jsp (última entrada: 26/06/2019).

LATINOBARÓMETRO (2018a): Latinobarómetro, página inicial. Recuperado a partir de http:// www.latinobarometro.org/lat.jsp (última entrada: 26/06/2019).

LATINOBARÓMETRO (2018b): Latinobarómetro, Corporación Latinobarómetro. Recuperado a partir de http://www.latinobarometro.org/latContents.jsp. LATINOBARÓMETRO (2018c): Latinobarómetro, Análisis de datos. Recuperado a partir de http://www. latinobarometro.org/latOnline.jsp (última entrada: 26/06/2019).

LEÃO, RODRIGO PIMENTEL FERREIRA, PINTO, EDUARDO COSTA E ACIOLYLUCIANA (2011): A China na nova configuração global: impactos políticos e econômicos. Brasília: Ipea.

LOPES, RODRIGO HERRERO E HITNER, VERENA (2009): «Venezuela: o Papel dos Processos de Integração para a Manutenção do Governo Chávez», em: Cadernos PROLAM/USP, $\mathrm{n}^{\circ} 8$, vol. 2. 
MACADAR, BEKY MORON B. (2009): "As relações comerciais Brasil-Argentina: evolução recente», em: Indicadores Econômicos FEE, n 37, vol. 2. MARCHA0, TALITA (2017): «Mercosul impõe nova suspensão à Venezuela», Notícias Uol, Recuperado a partir de https://noticias.uol.com.br/internacional/ ultimas-noticias/2017/08/05/reuniao-da-cupulado-mercosul-decide-pela-suspensao-politicada-venezuela.htm?cmpid=copiaecola (última entrada: 26/06/2019).

MARQUES, FERNANDO (2016): «Realinhamento pragmático? A agenda externa dos primeiros 100 dias de Macri», em: International Centre for Trade and Sustainable Development, n 12, vol. 3.

MAYORGA, FERNANDO (2016): «Democracia na América Latina: mudanças e persistências», em: Revista USP, $\mathrm{n}^{\circ} 109$.

OBSERVATORY OF ECONOMIC COMPLEXITY (2017): Argentina, recuperado a partir de http://atlas.media. mit.edu/pt/profile/country/arg/\#Destino (última entrada: 26/06/2019).

OLIVEIRA, ODETE MARIA (1998): «A integração bilateral Brasil-Argentina: tecnologia nuclear e Mercosul», em; Revista Brasileira de Política Internacional, $\mathrm{n}^{\circ}$, vol.1.

PONTES (2016a): «Membros do Mercosul buscam, unilateralmente, acordos com terceiros países», em: International Centre for Trade and Sustainable Development, 26/10/2016. Recuperado a partir de http://pt.ictsd.org/bridges-news/pontes/ news/membros-do-mercosul-buscam-unilateralmente-acordos-com-terceiros-pa\%C3\%ADses (última entrada: 26/06/2019).

PONTES (2016b): «Mercosul: um tango argentino?», em International Centre for Trade and Sustainable Development, n 12 , vol. 3.
PONTES (2016c): «Venezuela é marginalizada, e presidência doMercosul será colegiada», em International Centre for Trade and Sustainable Development, 15/09/2016, recuperado a partir de http://pt.ictsd.org/bridges-news/pontes/ news/venezuela-\%C3\%A9-marginalizada-epresid\%C3\%AAncia-do-mercosul-ser\%C3\%A1colegiada (última entrada: 26/06/2019).

PONTES (2017): «Populismo: um convite ao isolamento?», em International Centre for Trade and Sustainable Development, n 13, vol. 4. ROLON, JOSÉ APARECIDO (2010): Paraguai: transição democrática e política externa, Doutorado em Ciência Política, Faculdade de Filosofia, Letras e Ciências Humanas da Universidade de São Paulo. SILVA, ROBERTA RODRIGUES MARQUES (2012): «A política externa do Uruguai no período recente: as teorias das relações internacionais e os dilemas de um estado pequeno», em: VI Congreso de Relaciones Internacionales, Universidad Nacional de La Plata, 21, 22 y 23 de noviembre.

SCHENONI, LUIS L. (2012): «Ascenso y hegemonía: pensando a las potencias emergentes desde América del Sur», em: Revista Brasileira de Política Internacional, $\mathrm{n}^{\circ}$ 55, vol. 1.

VADELL, JAVIER A. (2006): «A Política Internacional, a Conjuntura Econômica e a Argentina de Néstor Kirchner», em: Revista Brasileira de Política Internacional, $\mathrm{n}^{\circ}$ 49, vol. 1.

VEIGA, PEDRO DA MOTA E RIOS, SANDRA P. (2007): «O regionalismo pós-liberal, na América do Sul: origens, iniciativas e dilemas», em: Série Comércio Internacional, CEPAL.

VIGEVANI, TULLO E CEPALUNI, GABRIEL (2007): «A política externa de Lula da Silva: a estratégia da autonomia pela diversificação», em: Contexto Internacional, n 29 , vol. 2. 